\title{
OS ESPAÇOS PÚBLICOS DE CONTROLE E INTERVENÇÃO SOCIAL ${ }^{1}$
}

\author{
Hugo Rosa da Paixão \\ hrpaixao@gmail.com
}

\begin{abstract}
RESUMO:
Passados vinte e dois anos do processo que culminou na promulgação da Constituição Federal de 1988, é possível fazermos uma releitura para avaliar progressos e retrocessos na consolidação do processo de democratização do país. Teóricos e estudiosos se dividem em seus posicionamentos, na medida em que para uns, o Estado brasileiro vem apresentando significativas modificações no quadro político, jurídico, social e econômico, em contra partida, outros afirmam que esse quatro é marcado por um intenso retrocesso, na medida em que os direitos foram inseridos na Carta Magna de 1988, mas não efetivado pelo governo brasileiro. Diante desse paradoxo, o presente trabalho apresentará mecanismos pautados em dados científicos, objetivando que o próprio leitor possa analisar e se posicionar nesse cenário. O trabalho analisa os espaços públicos destinados à participação social e intervenção na construção das políticas públicas, bem como nas importantes decisões que atingirá a vida da população.
\end{abstract}

Palavras-chave: espaço público, participação social, políticas públicas.

\begin{abstract}
After twenty-two year from the process that culminated on the promulgation of the 1988 Federal Constitution, it is possible to do a rereading in order to evaluate progress and retrogress on the consolidation of the country's democratization process. Theorists and studious stand up for different positions in the sense that for some of them, the Brazilian State has been presenting significant modifications on the political, juridical, social and economical framework. On the other hand, others state that this framework is outlined by an intense retrogress in the sense that the rights were introduced on the Federal Constitution of 1988, but they were not realized by the Brazilian government. Against this paradox, this paper will present mechanisms based on scientific data aiming that the reader can be able to analyze and take a position on such scenery. This work analyzes the public spaces designated to social participation and intervention on the construction of public policies, as well as on the important decision that will affect the life of the population.
\end{abstract}

Keywords: public space, social participation, public policies

\section{INTRODUÇÃO}

Uma das principais características da Constituição Federal de 1988 é o espaço que ela possibilita para a atuação do cidadão, no exercício da sua cidadania junto à Administração

\footnotetext{
${ }^{1}$ Esse artigo se configura como a última parte de um estudo maior, intitulado "Movimentos Sociais e a Constituição Federal: Mecanismos Jurídicos de Controle e Intervenção Social", realizado entre o final de 2008 e 2009, apresentado na Universidade São Francisco / Campus São Paulo.
} 
Pública. O Direito de Participação Social é consagrado na Ordem Jurídica, como um dos sustentáculos para a Democracia, no Estado brasileiro. Sobre ele, no ensina Marilena Chauí:

Participação no poder significava: que todos os cidadãos têm o direito de participar das discussões e deliberações públicas da polis, votando ou revogando decisões. Esse direito possuía um significado muito preciso. Nele afirmava-se que, do ponto de vista político, todos os cidadãos têm competência para opinar e decidir, pois a política não é uma questão técnica (eficácia administrativa e militar) nem científica (conhecimentos especializados sobre administração e guerra), mas ação coletiva, isto é, decisão coletiva quanto aos interesses e direitos da própria polis. (CHAUÍ, 2000, p. 559)

Essa abertura para a participação social legitima nasce com a Constituição Federal de 1988, na medida em que ela prever sistemas de gestão descentralizados nos mais diversos campos de atuação da Administração Pública.

Como exemplo disso pode-se destacar a abertura para a participação social da comunidade como uma das diretrizes para a organização das ações e serviços relativos à Saúde (CF, art. 198, III). Na Assistência Social, temos a previsão de que seja considerada como uma das diretrizes para as ações governamentais a participação da população, por meio de organizações representativas, na formulação das políticas e no controle das ações em todos os níveis $(\mathrm{CF}$, art. 204, II) Para a Seguridade Social, temos que ela será organizada de forma a observar o caráter descentralizado da administração, mediante a participação dos trabalhadores, empregados e aposentados (CF, art. 194, VII). No Meio Ambiente, exige a participação de toda a coletividade, do dever de preservação, proteção e defesa (CF, art. 225) e por fim, podemos indicar ainda, o dever de assegurar os direitos da criança e do adolescente, atribuído à família, ao Estado e a sociedade (CF, art. 227).

O processo de assegurar a participação social é atribuído ao Poder Executivo, na promoção das Políticas Públicas, quando deverá propiciar à população, os espaços para o debate das questões que envolvem determinado tema. Seguindo essa obrigatoriedade os espaços mais utilizados nos dias de hoje são: os Conselhos de Políticas Setoriais, as Conferências e as Audiências Públicas, os quais serão abordados a seguir.

\section{CONSELHOS DE POLÍTICAS SETORIAIS}

Sob o fundamento constitucional que protege a participação popular, os movimentos sociais, ao longo de anos de lutas, conquistam espaços significativos dentro da Administração Pública, na construção de políticas públicas e setoriais. Dentro deles podemos destacar os Conselhos de Políticas Setoriais, que se constituem como uma das formas de organização 
administrativa adotada com a finalidade de resguardar a participação dos cidadãos nas ações e decisões que culminarão em novas políticas públicas.

O conselho se configura como órgão administrativo colegiado com representantes da sociedade e do Poder Público. Segundo a Lei Federal 8.069/90, ao estabelecer a política de atendimento para o segmento Criança e o Adolescente, exige a criação de conselhos municipais, estaduais e nacionais, como órgãos deliberativos e controladores dessas ações. A sua formação de ser paritária, por meio de organizações representativas na forma da lei (ECA, art.88, II).

Os conselhos têm como objeto, debater questões que envolvem políticas setoriais, influenciando assim na construção de uma política democrática e participativa. Suas principais características são: a) a independência dos Órgãos Governamentais para o exercício das suas competências; b) a competência para intervir nas formulações de políticas públicas, atuando como mecanismo deliberador; c) a execução de políticas por ele desenvolvidas, coordenando ações, fiscalizando e em muitos casos, gerindo fundos, destinados a política setorial e, d) a composição paritária entre membros do Poder Publico e à Sociedade Civil.

A autonomia dos conselhos permite o desenvolvimento de suas atividades independentemente do governo em exercício, lhe garantido a liberdade necessária para atuar, pressionando o Executivo, quando se fizer necessário acerca de determinada situação. É preciso apontar que, para se resguardar tal autonomia, é importante a criação do conselho por meio de lei especifica, estabelecendo as competências, as matérias pelas quais será objetos de deliberações, forçando a Administração Pública a se vincular às deliberações do colegiado, vendo-se do Principio da Legalidade Estrita. Como exemplo do que se afirma acima, é o acesso a Saúde Pública como um direito de todos, nos temos do art. 196 - CF e às normas para a participação social, conforme segue.

Art. 196 - A saúde é direito de todos e dever do Estado, garantido mediante políticas sociais e econômicas que visem à redução do risco de doença e de outros agravos e ao acesso universal e igualitário às ações e serviços para sua promoção, proteção e recuperação. (Constituição Federal 1988)

A norma constitucional é taxativa, na medida em que impõem como diretriz para a organização das ações e prestação de serviços públicos na área da saúde, a descentralização (art. 196, I) bem como a participação da comunidade (art. 196, II), para tanto, esses dispositivos são regulamentados pelas Leis 8080/1990, que dispõe sobre as condições para a promoção, proteção e recuperação da saúde, bem como sobre organização e o funcionamento dos serviços a ela correspondentes e 8142/1990 que dispõe sobre a participação social na gestão do SUS Sistema Único de Saúde. Sobre o Conselho de Saúde, considerado por muitos, um avanço 
significativo na legislação brasileira, pois deposita na participação social a responsabilidade de gerir juntamente com o Poder Público os respectivos serviços de saúde pública, conforme segue:

Art. $1^{\circ}$ O Sistema Único de Saúde (SUS), de que trata a Lei $n^{\circ} 8.080$, de 19 de setembro de 1990, contará, em cada esfera de governo, sem prejuízo das funções do Poder Legislativo, com as seguintes instâncias colegiadas: I - a Conferência de Saúde; e II - o Conselho de Saúde. (Lei 8.142/90)

A lei que regulamenta a participação da sociedade civil na gestão do SUS - Sistema Único de Saúde, não apresenta um rol fechado de competências para os conselhos de saúde, permitindo, que cada instância de governo se responsabilize por determinar tal competência, entretanto, ela impõe normas para a instituição do conselho, determinando que ele seja permanente e de caráter deliberativo, além de paritários, definindo ainda a sua composição.

Outra inovação dessa lei é a composição do órgão colegiado a ser composto por representantes do governo, prestadores de serviço, profissionais de saúde e usuários, além de delimitar a função do Conselho, que atuará na formulação de estratégias e no controle da execução da política de saúde na instância correspondente, inclusive nos aspectos econômicos e financeiros $\left(\operatorname{art.} 1^{\circ}, \S 2^{\circ}\right.$ ), impondo ainda, que as decisões ali proferidas sejam homologadas pelo chefe do poder legalmente constituído em cada esfera do governo. Para que os conselhos possuam uma efetiva atuação na defesa dos direitos dos cidadãos, é preciso que os movimentos co-relacionados atuem intensamente, principalmente na construção da lei que regerá a atuação do conselho, com o fim de resguardar que este instrumento possua abertura para a participação social tal qual a Lei 8.142/1990, já considerada referência os conselhos.

Abaixo apresentamos a sistematização de uma pesquisa, realizada em 2009, sobre os conselhos de políticas setoriais, dentro da Administração Pública.

Quadro 01: Conselhos de Participação Popular - Esferas Federal ${ }^{2}$, Estadual ${ }^{3}$ e Municipal $^{4}$.

\begin{tabular}{|c|c|c|}
\hline Esfera Federal & Esfera Estadual (São Paulo) & Esfera Municipal (São Paulo) \\
\hline $\begin{array}{c}\text { Conselho de Desenvolvimento } \\
\text { Econômico e Social }\end{array}$ & $\begin{array}{c}\text { Conselho Estadual de } \\
\text { Participação e Desenvolvimento } \\
\text { da Comunidade Nordestina }\end{array}$ & $\begin{array}{c}\text { Conselho Municipal de Preservação } \\
\text { ao Patrimônio Histórico }\end{array}$ \\
\hline $\begin{array}{c}\text { Conselho Nacional dos Direitos do } \\
\text { Idoso }\end{array}$ & $\begin{array}{c}\text { Conselho Estadual da Condição } \\
\text { Feminina }\end{array}$ & $\begin{array}{c}\text { Conselho Municipal de Assistência } \\
\text { Social }\end{array}$ \\
\hline $\begin{array}{c}\text { Conselho Nacional de Aqüicultura e } \\
\text { Pesca }\end{array}$ & $\begin{array}{c}\text { Conselho Estadual dos Povos } \\
\text { Indígenas de São Paulo }\end{array}$ & $\begin{array}{c}\text { Conselho Municipal de Álcool e } \\
\text { Drogas }\end{array}$ \\
\hline $\begin{array}{c}\text { Comissão Nacional de Erradicação } \\
\text { do Trabalho Escravo }\end{array}$ & $\begin{array}{c}\text { Conselho Estadual da Criança e } \\
\text { do Adolescente }\end{array}$ & $\begin{array}{c}\text { Conselho Municipal dos Direitos da } \\
\text { Criança e do Adolescente }\end{array}$ \\
\hline Conselho Nacional das Cidades & Conselho Estadual de Juventude & Conselho Municipal de Deficientes \\
\hline Conselho Nacional de Turismo & Conselho Estadual do Idoso & Conselho Municipal de Educação \\
\hline
\end{tabular}

\footnotetext{
${ }^{2}$ BRASIL, Portal do Governo Federal. Disponível em: http://planalto.gov.br - 09/11/2009.

${ }^{3}$ BRASIL, Portal do Executivo Estadual de São Paulo. Governo do Estado de São Paulo - Sec. de Relações Institucionais. Disponível em http://www.relacoesinstitucionais.sp.gov.br/portal.php/conselhos - 09/11/2009.

${ }^{4}$ BRASIL, Portal do Executivo Municipal de São Paulo. Disponível em http://prefeitura.sp.gov.br/conselho $09 / 11 / 2009$
} 


\begin{tabular}{|c|c|}
\hline Conselho Nacional de Cultura & Conselho Municipal de Habitação \\
\hline Conselho Nacional das Cidades & Conselho Municipal de Informática \\
\hline $\begin{array}{l}\text { Conselho Nacional de Promoção da } \\
\text { Igualdade Racial }\end{array}$ & Conselho Municipal do Idoso \\
\hline $\begin{array}{c}\text { Conselho Nacional de } \\
\text { Desenvolvimento Rural Sustentável }\end{array}$ & $\begin{array}{c}\text { Conselho Municipal do Meio } \\
\text { Ambiente }\end{array}$ \\
\hline Conselho Nacional da Juventude & Conselho Municipal de Turismo \\
\hline Conselho Nacional de Turismo & Conselho Municipal de Saúde \\
\hline $\begin{array}{c}\text { Conselho Brasileiro do Mercosul } \\
\text { Social e Participativo }\end{array}$ & $\begin{array}{l}\text { Conselho Municipal de Direitos } \\
\text { Humanos }\end{array}$ \\
\hline $\begin{array}{c}\text { Conselho Nacional de Segurança } \\
\text { Alimentar e Nutricional }\end{array}$ & $\begin{array}{c}\text { Conselho Municipal de Direitos } \\
\text { Humanos }\end{array}$ \\
\hline $\begin{array}{l}\text { Conselho de Defesa dos Direitos da } \\
\text { Pessoa Humana }\end{array}$ & $\begin{array}{l}\text { Conselho Municipal de Assistência } \\
\text { Social }\end{array}$ \\
\hline $\begin{array}{l}\text { Conselho Nacional da Criança e do } \\
\text { Adolescente }\end{array}$ & $\begin{array}{c}\text { Conselho Municipal de Drogas e } \\
\text { Álcool }\end{array}$ \\
\hline $\begin{array}{c}\text { Conselho Nacional de Combate à } \\
\text { Discriminação }\end{array}$ & $\begin{array}{c}\text { Conselho Municipal dos Direitos da } \\
\text { Criança e do Adolescente }\end{array}$ \\
\hline Conselho Nacional das Pessoas Portadoras de Deficiência & Conselho Municipal de Deficientes \\
\hline Conselho de Desenvolvimento Econômico e Social & Conselho Municipal de Educação \\
\hline Conselho Nacional dos Direitos do Idoso & Conselho Municipal de Habitação \\
\hline Comissão Nacional de Erradicação do Trabalho Escravo & Conselho Municipal de Juventude \\
\hline \multicolumn{2}{|c|}{ Conselho Nacional de Economia Solidária } \\
\hline \multicolumn{2}{|c|}{ Conselho Nacional dos Direitos da Mulher } \\
\hline \multicolumn{2}{|c|}{ Conselho Nacional de Segurança Alimentar e Nutricional } \\
\hline \multicolumn{2}{|c|}{ Conselho Nacional de Economia Solidária } \\
\hline \multicolumn{2}{|c|}{ Conselho Nacional de Aqüicultura e Pesca } \\
\hline
\end{tabular}

\section{AUDIÊNCIAS PÚBLICAS}

Fundado no Direito ao Acesso de Informação (CF - Art. 5, XIV), bem como no Principio Constitucional da Publicidade que rege a Administração Pública (CF, art. 37, caput), as Audiências Públicas configuram-se como o meio pelo qual o Estado, por quaisquer de seus poderes, promovam o debate de forma aberta e transparente, sobre matéria de interesse social.

A Constituição Federal 1988 determina que haja a cooperação das associações representativas no planejamento municipal (art. 29, XII); permite a participação da comunidade na gestão da seguridade social (art. 194, § único, VII); determina a participação da sociedade na gestão da saúde pública (arts. 198, III, 204, II) além de institui a realização de audiências impondo à coletividade o dever de atuar para a defesa e preservação do meio ambiente (art. 225). Essas ações são realizadas por meio das Audiências Públicas, transformando-as em um importante espaço para a Participação Popular, uma vez que elas podem ser entendidas como um meio de garantir o exercício pleno da Cidadania na construção de políticas de interesse social.

Nessa linha, Diogo de Figueiredo Moreira Neto ao definir o espaço de interlocução entre sociedade civil e Administração Pública, destaca: 
A audiência pública é um instituto de participação administrativa aberta a indivíduos e a grupos sociais determinados, visando à legitimidade da ação administrativa, formalmente disciplinada em lei, pela qual se exerce o direito de expor tendências, preferências e opções que podem conduzir o Poder Público a uma decisão de maior aceitação consensual. (NETO, 1992, p. 192)

Ela deve ser utilizada como uma garantia processual na defesa dos direitos coletivos e difusos, ao passo que esses foram lesados ou encontrarem-se ameaçados por ato administrativo, projetos de lei em tramitação, ou ainda, decisão judicial de relevante repercussão nacional.

A competência para chamar as Audiências Públicas, foi conferida pela Constituição Federal de 1988, ao Congresso Nacional, quando a matéria for de competência do Legislativo Federal. Sendo ela de competência dos Estados, Distrito Federal e municípios, o fundamento será as constituições estaduais ou leis orgânicas municipais e do Distrito Federal.

No ordenamento jurídico brasileiro, é competente ainda para convocar Audiência Pública: a) Supremo Tribunal Federal: Conforme Regimento Interno, por meio do Presidente (art. 13, XVII) ou Relator (art. 21, XVII), com o fim de ouvir pessoas com experiência e autoridade em determinada matéria, sempre que entender necessário para o melhor o esclarecimento de questões ou circunstâncias de fato, com repercussão geral e de interesse público. b) Ministério Público: Conforme a sua Lei Orgânica 8.625/93, quando se fizer necessário a defesa dos direitos assegurados nas Constituições Federal ou Estaduais (art. 27, IV). c) O juízo competente em processo administrativo: Lei Federal 9.784/1999 ao reafirmar a necessidade de que a população seja ouvida por meio de audiências públicas quando a matéria envolver assunto de interesse geral (art. 31). d) Aos Deputados Estaduais e Vereadores: no âmbito dos seus Regimentos Internos; e, e) Aos moradores e associações: No município de São Paulo, por força da Lei Orgânica Municipal (art. 159).

A realização das Audiências Públicas pode ser entendida como o cumprimento de duas funções: a) o dever constitucional de manter a sociedade informada, e nos casos de questões de relevante interesse social propor o debate, esclarecendo à comunidade, na presença de técnicos e, b) colher opinião dos cidadãos, que poderão apresentar propostas para eventuais problemas, e definir prioridades para a Gestão Pública, quando esse for seu objeto. Quanto à vinculação da Administração Pública, para com o resultado da Audiência, aponta Gustavo Justino de Oliveira:

(...) constatando que os institutos participativos têm lugar, notadamente, no âmbito da atividade administrativa discricionária, eventual posicionamento da população firmado em sede de audiência pública é mais um elemento na limitação da liberdade de atuação da Administração. Ainda que não vinculante, as exposições dos interessados devem ser minuciosamente consideradas pelo órgão "decididor" podendo inclusive constituir-se na motivação expressa de sua decisão. (OLIVEIRA, 1997, p. 163) 
A questão da vinculação ou não das decisões proferidas em sede de Audiências Públicas e dos Conselhos de Políticas Setoriais, conforme apontado está ligado à existência de lei que a defina e obrigue a Administração Pública a se vincular, assim se ela terá o efeito vinculante e não apenas consultivo.

Nesse sentido apontamos dois casos peculiares, o primeiro emana da Resolução 009/87 do CONAMA - Conselho Nacional de Meio Ambiente, que impõe a obrigatoriedade de realização de Audiência Pública para a aprovação do RIMA - Relatórios de Impacto Ambiental, sob pena de nulidade da licença ambiental concedida.

O segundo caso ocorre no município de São Paulo, que por força da Lei Orgânica determina a vinculação na aprovação, condicionada à realização de Audiências Públicas, para debater projetos de implantação de obras ou equipamentos com repercussão ambiental (art. $159, \S 1^{\mathrm{o}}$ e $2^{\mathrm{o}}$ ).

Tal inobservância pode configurar vício na edição de leis ou atos normativos da Administração Pública, sendo passivo de Mandado de Segurança ou se for o caso, a oposição de Ação Direta de Inconstitucionalidade, desde que observados os requisitos legais.

\section{CONFERÊNCIAS PÚBLICAS}

Dentro desse novo contexto de participação social que a Democracia brasileira atravesse, podemos destacar as Conferências Públicas como um importante espaço para a atuação do cidadão, seja na construção de políticas públicas setoriais, seja na tomada de decisões que poderão causar impacto em sua vida.

No processo de elaboração de políticas públicas ou mesmo de políticas setoriais temos como outro ponto importante para o exercício pleno da cidadania, constituído também como um espaço público, democrático e diversificado para a atuação dos diversos segmentos sociais, é a realização das Conferências Públicas.

Por conferências públicas, entendemos como sendo o espaço político para a reflexão necessária em torno de determinado tema, com o fim de traçar diretrizes gerais para uma determinada política pública ou setorial, onde governo e sociedade civil expõem os seus pontos de vistas a fim de se chegar a um denominador comum.

Ao analisarem o tema em questão, em virtude da ocorrência da I ${ }^{a}$ Conferência Nacional de Juventude, a socióloga Patrícia Lânes e o cientista político Maurício Santoro relatam ao 
Observatório Jovem ${ }^{5}$, o avanço do processo de redemocratização pelo qual passa o país, conforme se transcreve a seguir:

(...) a realização de conferências que reúnem representantes da sociedade civil e do governo para debater os rumos das políticas públicas é uma das inovações da redemocratização do Brasil. Desde a década de 1980, consolidaram-se iniciativas participativas como essas em setores como proteção à criança e ao adolescente, saúde e direitos humanos, que já realizaram dezenas de conferências. Outros campos, como políticas de promoção da igualdade racial e de defesa dos direitos das mulheres, têm experiência bem mais recente com tais medidas.

Ao passo em que o país vai aos poucos construindo a sua Democracia, com a tomada de consciência do cidadão de que ele é parte significativa nesse processo, o Instituto Polis Organização Não Governamental de assessoria aos movimentos sociais, alerta que as conferências devem ser entendidas como o espaço de debate entre Poder Público e Sociedade, nos tempos que segue:

As conferências de políticas públicas são espaços amplos e democráticos de discussão das políticas, gestão e participação. Sua principal característica é reunir governo e sociedade civil organizada para debater e decidir as prioridades nas políticas públicas nos próximos anos. Na medida em que os diversos segmentos envolvidos com o assunto em questão participam do debate promovido na realização de uma conferência, pode-se estabelecer um pacto para alcançar determinadas metas e prioridades, além de abrir um espaço importante de troca de experiências. Podem ser realizadas conferências em âmbito municipal, estadual e federal. (BOLETIM POLIS No 230$)^{6}$

Segundo aponta o IPEA - Instituto de Pesquisa Econômica Aplicada, no relatório denominado Participação Social: Retrato da trajetória recente ${ }^{7}$ a intensificação da realização de conferências nacionais é marco característico da gestão dos últimos anos, realizada pelo Partido dos Trabalhadores, conforme segue:

No Brasil com a assunção ao poder de uma das forças políticas originárias do sindicalismo e dos movimentos sociais criados nas décadas de 70 e 80 tem-se observado a maior presença da sociedade nos espaços de participação social existentes na esfera pública federal. Informações referentes ao período 2003 a 2006 indicam que nesse período o governo federal colocou em prática uma estratégia de manter e ampliar a interlocução com movimentos sociais e com organizações da sociedade. Tal estratégia foi concretizada a partir da maior utilização dos espaços de participação social existentes no âmbito da administração pública federal e da criação de novos mecanismos que propiciam a canalização das demandas e manifestações da sociedade para dentro do Estado. (RELATORIO IPEA 2007)

\footnotetext{
${ }^{5}$ BRASIL, Portal do Observatório Jovem - Democracia e Participação: Reflexões da $1^{a}$ Conferencia de Políticas $\begin{array}{lllll}\text { Públicas para } & a & \text { Juventuder } & \text { Disponível }\end{array}$ http://www.uff.br/obsjovem/mambo/index.php?option=com_content\&task=view\&id=492. Acesso em 09/11/2009.

${ }^{6}$ BRASIL, Portal do Instituto Polis - Boletim Dicas: Governo e Sociedade - Conferências Públicas. Disponível em http://www.polis.org.br/publicacoes/dicas/dicas_interna.asp?codigo=230. Acesso: 09/11/2009.

7 BRASIL, Portal do IPEA - Participação Social: Retrato da trajetória recente. Disponível em http://www.ipea.gov.br/sites/000/2/textos/resumo\%20sem_quintas\%20part_social.pdf. Acesso em 10/11/2009.
} 
As conferências surgem como demanda dos Conselhos de Políticas Setoriais, que identificam a demanda social para debate de determinada política setorial ou pública, podendo ainda ser instituída por força de lei. Como exemplificação, podemos apontar a Conferência Nacional de Saúde, instituída como instância colegiada, para a organização do Sistema Único de Saúde, de acordo com as disposições contidas na Lei Federal 8.142/1990, art. $1^{\circ}$, I.

Nessa mesma linha, importa ainda destacar as disposições do parágrafo único, da mesma lei, que institui normas especificas a serem aplicadas na respectiva conferencia, conforme segue:

A Conferência de Saúde reunir-se-á a cada quatro anos com a representação dos vários segmentos sociais, para avaliar a situação de saúde e propor as diretrizes para a formulação da política de saúde nos níveis correspondentes, convocada pelo Poder Executivo ou, extraordinariamente, por esta ou pelo Conselho de Saúde. (Lei Federal 8.142/1990)

Nos casos em que não exista disposição legal para a convocação das conferências em qualquer que seja o âmbito da esfera de governo, essa será feita por atribuição do Poder Executivo, por meio do Chefe do Executivo, ou Chefes de Ministérios ou Secretarias. Salvo disposição legal contrario, a convocação é feita por meio de Decreto do Poder Executivo, o qual traçará normas sobre a realização da conferência, podendo ainda, designar a comissão organizadora que será composta, obrigatoriamente por representantes da Sociedade Civil e do Poder Público, a sua presidência será sempre exercida por aquele que a convocou.

Com a intenção de se reunir na Conferência Nacional, o maior número de propostas geralmente se realiza pré-conferencias municipais, com o fim de garantir a participação social, nessa linha é importante apontar as orientações do Instituto Polis, conforme segue:

Após o processo das pré-conferências, a equipe organizadora deve sistematizar e analisar o material colhido nas reuniões preparatórias, para compor o ponto de partida da conferência municipal. A elaboração de materiais apropriados, em linguagem simples, é importante para que os delegados se apropriem do que será discutido. Por ter duração prolongada, a conferência pode ocorrer, por exemplo, em um sábado. A prefeitura pode fornecer alimentação e transporte aos participantes, evitando ausências por problemas financeiros dos delegados. É importante também oferecer uma estrutura de apoio às mulheres que tenham filhos pequenos, para que esta condição não limite sua participação. (BOLETIM POLIS - Informativo $n^{\circ} 230$ )

Com a eleição dos delegados e das propostas nas pré-conferências, se realizará a Conferência Municipal, da qual se extrai nova delegação e rol de novas propostas para a Estadual, para só então, com novos delegados e propostas eleitas na Conferência Estadual, se realizará a Conferência Nacional. Esse método apresentado não é obrigatório, trata-se tão simplesmente de tornar o processo mais democráticos, resguardado assim a participação de um número maior de pessoas. A participação na conferência é direito de todos os cidadãos, os quais detêm livremente o direito de votar e serem votados, como delegados, bem como a indicar propostas e nelas votarem, desde que atenda os requisitos instituídos no Regimento Interno. 
O Regimento Interno é a norma máxima de uma conferência, e deverá conter obrigatoriamente a programação, o tempo a ser destinado para os painéis de debates bem como, a apresentação, se for o caso, dos conferencistas e autoridades, devendo ser construído pela Comissão Organizadora e submetido à votação no plenário geral.

Durante a conferência, são formados Grupos de Trabalhos, os quais são definidos por eixo de discussão do tema central como, por exemplo, saúde, educação, geração de emprego e renda. Dos GT's, serão extraídas as propostas, de acordo com o número estabelecido previamente pelo regimento interno, sendo que após a aprovação pela Plenária Geral passa à memória da Conferência como Resolução. Submetidas as propostas à Plenária Geral, será escolhido por votação simples, de todos os participantes, as propostas de acordo com as determinações do Regimento Interno, sendo que essas, passarão a ser consideradas nas Resoluções ou Diretrizes a serem apresentadas na conferência seguinte.

Em 2007, segundo levantamento do IPEA - Instituto de Pesquisa Econômica Aplicada, no relatório denominado Participação Social: Retrato da trajetória recente ${ }^{8}$ verifica-se uma intensificação na propositura e realização das conferências nacionais dentro do território brasileiro, conforme segue:

Entre 2003 e 2006 foram realizadas no Brasil 43 Conferências Nacionais (com a participação de mais de dois milhões de pessoas que deliberaram sobre propostas relacionadas às mais diversas políticas públicas, resultando em, aproximadamente, 5 mil deliberações). Do total de conferências ocorridas nesse período, 15 foram realizadas pela primeira vez demonstrando a ascensão de novos atores e de temas no âmbito da política nacional. (IPEA 2007)

Com o fim de enriquecer a reflexão ora apresentada, procedemos a um levantamento das conferências nacionais realizadas entre 2003/2009, as quais, segundo dados do Governo Federal, registraram a participação de mais de 4 milhões de brasileiros nas 57 conferências nacionais para debater e aperfeiçoar políticas públicas.

Quadro 02: Histórico das Conferências Nacionais (2003/2009) ${ }^{9}$ :

\begin{tabular}{|l|l|}
\hline \multicolumn{1}{|c|}{ Governo Federal } & Ano de Realização \\
\hline Conferência Nacional de Aprendizagem Profissional & 2008 \\
\hline Conferência Nacional de Aqüicultura e Pesca & $2003 / 2006 / 2009$ \\
\hline Conferência Brasileira sobre Arranjos Produtivos & $2004 / 2005 / 2007$ \\
\hline Conferência Nacional de Assistência Social & $2003 / 2005 / 2007$ \\
\hline Conferência Nacional das Cidades & $2003 / 2005 / 2007$ \\
\hline Conferência Nacional de Ciência, Tecnologia e Inovação & 2005 \\
\hline Conferência Nacional de Ciência, Tecnologia e Inovação em Saúde & 2004 \\
\hline Conferência das Comunidades Brasileiras no Exterior & $2008 / 2009$ \\
\hline
\end{tabular}

8 BRASIL, Portal do IPEA - Participação Social: Retrato da trajetória recente. Disponível em http://www.ipea.gov.br/sites/000/2/textos/resumo\%20sem_quintas\%20part_social.pdf. Acesso em 10/11/2009.

\footnotetext{
${ }^{9}$ BRASIL, Portal Governo Federal - Conselhos e Conferências: Sociedade participa da formulação de políticas.
} Disponível: http://wikicoi.planalto.gov.br/coi/Caderno_Destaques/Conselhos_conferencias.pdf. Em 09/11/2009. 


\begin{tabular}{|l|l|} 
Conferência Nacional de Cultura & 2005 \\
\hline Conferência Nacional de Desenvolvimento Rural Sustentável e Solidário & 2008 \\
\hline Conferência Nacional dos Direitos da Criança e do Adolescente & $2003 / 2005 / 2007$ \\
\hline Conferência Nacional dos Direitos da Pessoa com Deficiência & $2006 / 2008$ \\
\hline Conferência Nacional dos Direitos da Pessoa Idosa & $2006 / 2009$ \\
\hline Conferência Nacional de Direitos Humanos & $2003 / 2004 / 2006 / 2008$ \\
\hline Conferência Nacional de Economia Solidária & 2006 \\
\hline Conferência Nacional da Educação Básica & 2008 \\
\hline Conferência Nacional de Educação Profissional Tecnológica & 2006 \\
\hline Conferência Nacional do Esporte & $2004 / 2006$ \\
\hline Conferência Nacional de Gays, Lésbicas, Bissexuais, Travestis e Transexuais & 2008 \\
\hline Conferência Nacional de Gestão do Trabalho e da Educação na Saúde & 2005 \\
\hline Conferência Nacional Infanto-Juvenil do Meio Ambiente & $2003 / 2006 / 2009$ \\
\hline Conferência Nacional da Juventude & 2008 \\
\hline Conferência Nacional de Medicamentos e Assistência Farmacêutica & 2003 \\
\hline Conferência Nacional do Meio Ambiente & $2003 / 2005 / 2008$ \\
\hline Conferência Nacional das Políticas Públicas para as Mulheres & $2004 / 2007$ \\
\hline Conferência Nacional dos Povos Indígenas & 2006 \\
\hline Conferência Nacional de Promoção da Igualdade Racial & $2005 / 2009$ \\
\hline Conferência Nacional de Recursos Humanos da Administração Pública Federal & 2009 \\
\hline Conferência Nacional de Saúde & $2003 / 2007$ \\
\hline Conferência Nacional de Saúde Bucal & 2004 \\
\hline Conferência Nacional de Saúde do Trabalhador & 2005 \\
\hline Conferência Nacional de Saúde Indígena & 2006 \\
\hline Conferência Nacional de Segurança Alimentar e Nutricional & $2004 / 2007$ \\
\hline Conferência Nacional de Segurança Pública & 2009 \\
\hline Conferência Nacional de Comunicação & 2009 \\
\hline & \\
\hline
\end{tabular}

\section{CONCLUSÃO}

Dados os elementos acima, verificamos a existência de ações realizadas pelo Estado brasileiro e Sociedade Civil, com o objetivo dar aplicabilidade ao Texto Constitucional, o qual garante a participação do cidadão no processo de planejamento e decisões da gestão da Res pública, além de abrir a ele a participação na fase de fiscalização da execução das ações. As aberturas institucionais promovidas pelo Estado permitem uma aproximação maior entre os principais atores sociais, a saber, o Estado, a Sociedade Civil e o próprio individuo no exercício da sua cidadania. Nessa Maria Sylvia Zanella Di Pietro ressalta que a participação popular é uma “característica essencial do Estado de Direito Democrático, porque ela aproxima mais o particular da Administração, diminuindo ainda mais as barreiras entre o Estado e a Sociedade".

O exercício dessas práticas, pelos governos e pela sociedade potencializa a participação social na medida em que promove transparência nas deliberações e visibilidade nas ações da gestão pública, isso permite a democratização do sistema de decisões em cada esfera pública. Tal abertura permite uma maior expressão e visibilidade das demandas apresentadas pelos diferentes 
segmentos sociais, fomentando um avanço significativo na promoção da isonomia e eqüidade na construção das políticas públicas e setoriais.

Mesmo com tantos avanços, essas primeiras décadas do processo de democratização no país, é preciso considerar a necessidade de levar ao conhecimento de grande parte da população, a existência desses espaços para a sua atuação, promovendo e difundindo assim uma nova cultura de participação política no país, oferecendo uma contraposição à cultura assistencialista e de acomodação pela qual atravessa grande parte do povo brasileiro. É imprescindível que se desenvolva ações conjuntas e transversais que possam intervir dentro das realidades das massas sociais, com o objetivo de promover o debate sobre a Coisa Pública. Tais ações devem transcender aos limites impostos pelo senso comum, pela burocracia pública e principalmente pelas concepções antiquadas de governantes e seus respectivos partidos políticos.

A construção dessa nova Cultura de Participação Social deve ter como base uma Política Nacional de Educação Popular para a Democracia, a qual deverá congregar ações realizadas pelas diversas pastas institucionais do Estado, bem como dos diversos segmentos civis e sociais.

\section{REFERÊNCIAS}

BENEVIDES, Maria Victoria de Mesquita. A Cidadania Ativa: Referendo, Plebiscito e Iniciativa Popular. $3^{\text {a }}$ Edição - São Paulo, Editora Ática, 1998.

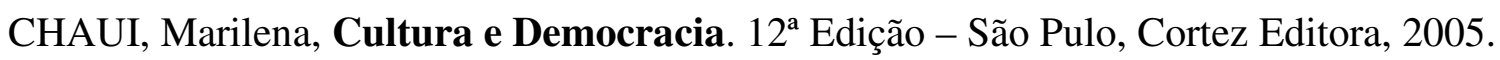
, Convite à Filosofia, Editora Ática 2000.

DALLARI, Dalmo de Abreu. O renascer do Direito. São Paulo, Editora Saraiva, 1996.

NETO, Diogo de Figueiredo Moreira. Direito de Participação Política: legislativa, administrativa, judicial: fundamento e técnicas constitucionais de legitimidade. Renovar, Rio de Janeiro, 1992.

Gustavo Henrique Justino de Oliveira, As Audiências Públicas e o Processo Administrativo Brasileiro, Revista de Direito Administrativo, Rio de Janeiro, 209: 153-167, jul/set. 1997. PIETRO, Maria Sylvia Zanella Di. Participação Popular na Administração Pública. Revista de Direito Administrativo, Rio de Janeiro, v.191, jan/mar 1993.

TOURAINE, Alain. O que é a Democracia? Petrópolis/RJ, Editora Vozes, 1996. 